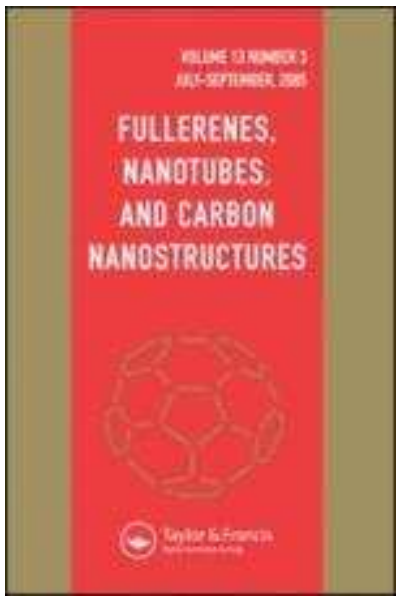

\title{
Production of Carbon Nanotubes over Fe-FSM-16 Catalytic Material: Effect of Acetylene Flow Rate and CVD Temperature
}

\begin{tabular}{|r|l|}
\hline Journal: & Fullerenes, Nanotubes and Carbon Nanostructures \\
\hline Manuscript ID: & FNCN1148.R1 \\
\hline Manuscript Type: & Original Article \\
\hline Author: & $\mathrm{n}$ Sabmitted by the \\
\hline Complete List of Authors: & $\begin{array}{l}\text { Taş, Sinem; Sabanci University, Faculty of Engineering and Natural } \\
\text { Sciences } \\
\text { Okyay, Firuze; Sabanci University, Faculty of Engineering and } \\
\text { Natural Sciences } \\
\text { Sezen, Meltem; Sabanci University, Nanotechnology Research and } \\
\text { Application Center } \\
\text { Plank, Harald; Graz University of Technology, Institute for Electron } \\
\text { Microscopy and Fine Structure Research } \\
\text { Yürüm, Yuda; Sabanci University }\end{array}$ \\
\hline Keywords: & $\begin{array}{l}\text { Carbon Nanotubes, Chemical Vapor Deposition, FSM-16, Fe } \\
\text { Catalyst, Acetylene }\end{array}$ \\
\hline
\end{tabular}

\section{SCHOLARONE" Manuscripts}




\title{
Production of Carbon Nanotubes over Fe-FSM-16 Catalytic Material: Effect of Acetylene Flow Rate and CVD Temperature
}

Sinem Taş ${ }^{1}$, Firuze Okyay ${ }^{1}$, Meltem Sezen ${ }^{2}$, Harald Plank ${ }^{3}$ and Yuda Yürüm ${ }^{1 *}$

\author{
${ }^{1}$ Faculty of Engineering and Natural Sciences \\ Sabanci University, Orhanli, Tuzla, Istanbul 34956, Turkey \\ ${ }^{2}$ Nanotechnology Research and Application Center, Sabanci University, Orhanli, Tuzla \\ Istanbul 34965, Turkey \\ ${ }^{3}$ Institute for Electron Microscopy and Fine Structure Research, Graz University of Technology, \\ Steyrergasse 17, A-8010 Graz, Austria
}

\author{
*Corresponding Author: \\ Yuda Yürüm \\ Faculty of Engineering and Natural Sciences \\ Sabanci University, Orhanli, Tuzla, Istanbul 34956, Turkey \\ yyurum@sabanciuniv.edu
}




\section{Production of Carbon Nanotubes over Fe-FSM-16 Catalytic Material: Effect of Acetylene Flow Rate and CVD Temperature} Sinem Taş ${ }^{1}$, Firuze Okyay ${ }^{1}$, Meltem Sezen ${ }^{2}$, Harald Plank ${ }^{3}$ and Yuda Yürüm ${ }^{1 *}$

${ }^{1}$ Faculty of Engineering and Natural Sciences

Sabanci University, Orhanli, Tuzla, Istanbul 34956, Turkey

${ }^{2}$ Nanotechnology Research and Application Center, Sabanci University, Orhanli, Tuzla Istanbul 34965, Turkey

${ }^{3}$ Institute for Electron Microscopy and Fine Structure Research, Graz University of Technology, Steyrergasse 17, A-8010 Graz, Austria

In this article, a high-yield synthesis of high-quality CNTs using Fe catalysts trapped within channels of Folded Sheet Mesoporous Materials, FSM-16 by Chemical Vapor Deposition CVD using acetylene as a hydrocarbon source is reported. The effect of reaction temperature and acetylene flow rate on the formation of CNTs was investigated. It was found that the yield, diameter and quality of CNTs synthesized strongly depend on reaction temperature during CVD. The resulting materials were characterized by scanning electron microscopy (SEM), Raman spectroscopy, and thermogravimetric analysis (TGA). Our research found that carbon deposition, diameter and quality of the CNTs strongly depend on CVD temperature. However acetylene flow rate did not have any significant effect on diameter distribution. Raman measurement indicated that the synthesized products were MWCNTs. High-resolution transmission electron micrographs of samples reveal the multilayer sidewalls of individual MWCNTs with a diameter of $40 \mathrm{~nm}$, in which hollow and tubal structures were observed.

Keywords Carbon Nanotubes, Chemical Vapor Deposition, FSM-16, Fe Catalyst, Acetylene

\section{Introduction}

Discovery of carbon nanotubes (CNT) is an important stepping stone for the nanotechnological progress. Due to the strong knowledge on electrical and mechanical properties of CNTs, they propose many application fields; polymer reinforcements for composites; energy storage; and electronics (1). Because of a strong knowledge on electrieal and-mechanical properties of CNTs, they find many application fields including polymer reinforcements for 
composites, energy storage, and electronics (1). However Unfortunately, cost effective production of CNTs is an important issue. Generally, CNTs are synthesized by three different production methods;- These are are-discharge; laser ablation; and chemical vapor deposition (CVD)methods. Both arc discharge and laser ablation methods are very difficult to scale up. On the other hand, due to its simplicity, low cost, product purity and easily controlled growth factors, CVD is the most promising method for industrial scale production of CNTs (2).

Basically, CVD process is dissociation of hydrocarbon molecules on the metal catalyst at high temperatures $\left(500^{\circ} \mathrm{C}-1000^{\circ} \mathrm{C}\right)$ for a certain period of time. Precipitation of the carbon on the metal particles leads to formation of CNTs. Working conditions of CVD such as Temperature, hydrocarbon concentration, metal particle size, and-pretreatment of metallic catalyst, and time of the reaction synthesis time are the crucial parameters that affect the quality of final product. Depending on these parameters, single-wall carbon nanotubes (SWCNTs) and multi-wall carbon nanotubes (MWCNTs) can be produced (3). depending on reaction conditions (3).

Because of Since CVD process depends on catalytic decomposition of hydrocarbon molecules, the role of catalyst is important for ability of CNT formation. Metal particle size is crucial for control of CNT diameter. Supported catalysts ensure the control of particle size for the growth process. Ordered mesoporous molecular sieves are preferred as a support material because of high specific surface area, large pore volume, uniform pore structure, and tunable pore size varying from 2 to $10 \mathrm{~nm}$ (4). Among the mesoporous materials, FSM-16 is a good candidate because of its large and hexagonal pore structure with high specific surface area. Indeed, ordered structure of FSM-16 ensures the good dispersion of metal particles. When FSM16 is loaded with metal particles, it can be used as a catalyst for various reactions applications such as, CNT production, hydrogen storage, and adsorption.

To meet the demand for CVD eperation process, type of the metal loaded on the support material is critical. In previous earlier studies, researchers reported, transition metals such as Fe, $\mathrm{Ni}$, and $\mathrm{Co}$ are commonly used that $\mathrm{Fe}, \mathrm{Ni}$, and $\mathrm{Co}$ are the frequently used transition metals as catalysts for the CNTs production (5). In addition to these, Sc, Ti, V, Cr, Mn, Zn and combination of them are also used as a catalysts $(6,7)$. The performance of catalysis depends strongly on the ability of catalytic dissociation of a hydrocarbon molecule. $3 \mathrm{~d}$ metals have als been attractive by means of obtaining nanotubes with better performance. Fe, Ni and Co and their combinations as catalysts offer attractive routes for the synthesis of nanotubes due to the 
interactions of their partially filled $3 \mathrm{~d}$ orbitals with the valence orbitals of the carbon precursors (5).

There are many studies focused on Fe loaded catalysts. Various researchers applied different templates for Fe based catalysis. It is reported that interaction between metal particles and template affects the catalytic activity. Kukovecz et al. (8) obtained MWCNTs with Fe supported on mixtures of $\mathrm{Al}_{2} \mathrm{O}_{3}-\mathrm{SiO}_{2}$. Many researchers found that $\mathrm{Fe}$ loaded $\mathrm{SiO}_{2}$ is a promising catalyst for MWCNTs synthesis (9-13). Much previous work was oriented towards synthesis of MWCNTs on Fe supported silicon substrate (11-14). Zhao et al. (4) and Atchudan et al. (15) studied MWCNTs synthesis on Fe-MCM-41. However, so far, only Kobayashi et al. reported SWCNTs production over $\mathrm{Fe}\left(\mathrm{CH}_{3} \mathrm{COO}\right)_{2} / \mathrm{Co}\left(\mathrm{CH}_{3} \mathrm{COO}\right)_{2} \cdot 4 \mathrm{H}_{2} \mathrm{O}$ and $\mathrm{Co}\left(\mathrm{NO}_{3}\right)_{2} \cdot 6 \mathrm{H}_{2} \mathrm{O}$ impregnated FSM-16 (16). Although the uniformed mesopores could make the catalysts well dispersed in the Fe-FSM-16 molecular sieve, the Fe-FSM-16 catalysts had not been used efficiently to prepare carbon nanotubes with CVD method.

In the present study, we report the catalytic activity of Fe impregnated FSM-16 in the production of carbon nanotubes by the CVD method using acetylene as hydrocarbon source. The effect of different reaction temperatures and acetylene flow rate on the formation of CNTs was were investigated. The morphology and crystallinity of CNTs grown on Fe-FSM-16 catalyst were investigated using Scanning Electron Microscopy, Raman spectroscopy, and thermogravimetric analysis.

\section{Experimental}

\section{Synthesis of Fe-FSM-16}

According to previously published procedure (17), synthesis of FSM-16 were carried out by using kanemite $\mathrm{NaHSi}_{2} \mathrm{O}_{5} \cdot 3 \mathrm{H}_{2} \mathrm{O}$ and hexadecyltrimethylammonium bromide as a template??

An The impregnation method was described as follows: first the dried powder of as synthesized FSM-16 mixed with iron (III) nitrate nonahydrate $\left(\mathrm{Fe}\left(\mathrm{NO}_{3}\right)_{3} \cdot 9 \mathrm{H}_{2} \mathrm{O}\right)$, solutions with 4 wt $\%$ metal loadings. The resultant mixture was stirred at room temperature for 1 hour and then the excess water was removed by stirring at $70^{\circ} \mathrm{C}$. The sample was filtered, washed and dried at $80^{\circ} \mathrm{C}$. Finally, the Fe impregnated sample was calcinated at $550^{\circ} \mathrm{C}$ for 4 hours in order to remove surfactant.

Synthesis of Carbon Nanotubes 
Carbon nanotube production was performed by using a CVD system. $100 \mathrm{mg}$ of the synthesized catalyst was placed into a boat crucible and then put in the middle of the quartz tube ( $900 \mathrm{~mm}$ in length, $30 \mathrm{~mm}$ diameter) of the CVD system to ensure the isothermal conditions. The furnace was heated up to $300^{\circ} \mathrm{C}$ under $1000 \mathrm{~mL} / \mathrm{min}$ Ar flow for $30 \mathrm{~min}$ to stabilize the catalyst and to purge oxygen present in the furnace prior to the start of the flow of acetylene. Afterwards, the system was set to a temperature between $500^{\circ} \mathrm{C}$ and $800^{\circ} \mathrm{C}$ for the CNTs growth. When the temperature set for the experiment was attained, acetylene $(40 \mathrm{~mL} / \mathrm{min})$ diluted in $\mathrm{Ar}$ $(1200 \mathrm{~mL} / \mathrm{min})$ were introduced into the system. The flow of the acetylene was continued for 30 min in all experiments. The samples were cooled down to room temperature under an Ar atmosphere $(1000 \mathrm{~mL} / \mathrm{min})$.

To investigate the effect of the flow rate of acetylene the reaction temperature was set to $700^{\circ} \mathrm{C}$ (as described below the optimum temperature for CNT production) and the acetylene flow rate was changed in the range of $40-120 \mathrm{~mL} / \mathrm{min}$.

Carbon nanotube yield was calculated as,

$$
\text { Carbon Yield }=\frac{m_{\text {Total } C+\text { Catalyst }}-m_{\text {Catalyst }}}{\frac{\text { Flow rate of } \mathrm{C}_{2} \mathrm{H}_{2}(\mathrm{l} / \mathrm{min}) \times \text { Time }(\mathrm{min})}{22.4 \mathrm{l} / \mathrm{mol} \mathrm{of} \mathrm{C}_{2} \mathrm{H}_{2}} \times 26 \mathrm{~g} / \mathrm{mol} \text { of } \mathrm{C}_{2} \mathrm{H}_{2} \times \frac{24 \mathrm{~g} \text { of } \mathrm{C}}{26 \mathrm{~g} \text { of } \mathrm{C}_{2} \mathrm{H}_{2}}}
$$

where $\mathrm{m}_{\text {Total }} \mathrm{C}+$ Catalyst is the weight of carbon product and catalyst; $\mathrm{m}_{\text {Catalyst }}$ is the weight of catalyst used for CNTs growth.

Carbon deposition in an experiment $=\mathrm{m}_{\text {Total }} \mathrm{C}+$ Catalyst $-\mathrm{m}_{\text {Catalyst }}$

\section{Characterization Methods}

The synthesized metal-impregnated FSM-16 was characterized by XRD, surface analysis techniques using $\mathrm{N}_{2}$ adsorption-desorption isotherms. X-ray diffraction pattern were recorded with a Bruker AXS advance powder diffractometer equipped with a Siemens X-ray gun and Bruker AXS Diffrac PLUS software, using $\mathrm{Cu} \mathrm{Ka}$ radiation ( $\mathrm{k}=1.5418$ Angstrom ). The samples were scanned in the $2 \theta$ range of $2-10^{\circ}$, with step size of $0.01^{0}$. Specific surface areas, pore diameters and pore volumes were determined by Quantachrome NOVA 2200 series Surface Analyzer. The nitrogen adsorption/desorption isotherms were recorded at $77 \mathrm{~K}$. Prior to physisorption measurements, the samples were outgassed at $423 \mathrm{~K}$ for $4 \mathrm{~h}$. The specific surface 
area and pore volume of the pure and Fe loaded FSM-16 materials were calculated by using the BET and BJH methods.

Different characterization techniques were carried out to examine the CNTs growth on the catalyst particles. The diameter and uniformity of carbon nanotubes were examined with Leo G34-Supra 35VP scanning electron microscope (SEM). The TEM micrographs were acquired by an FEI Tecnai F20 instrument at $200 \mathrm{keV}$. Thermogravimetric Analysis (TGA) and Raman Spectroscopy were also used to recognize the quality of CNTs as well as amount of defects. Raman spectra of CNT samples were recorded on a Renishaw InVia Reflex Raman Microscopy System (Renishaw Plc.; New Mills, Wotton-under-Edge Gloucestershire, UK) with a $514 \mathrm{~nm}$ argon ion laser in the range of 100 to $3200 \mathrm{~cm}^{-1}$. TGA measurements were performed on a Netzsch STA 449 C Jupiter differential thermogravimetric analyzer (precision of temperature measurement $\pm 2^{\circ} \mathrm{C}$, microbalance sensitivity $<5 \mu \mathrm{g}$ ) under air atmosphere with a flow rate 50 $\mathrm{ml} / \mathrm{min}$, at a linear heating rate of $5^{\circ} \mathrm{C} / \mathrm{min}$.

\section{Results and Discussion \\ X-ray diffraction pattern of Fe-FSM-16}

Figure 1 shows the XRD patterns of FSM-16 and Fe-FSM-16. The peaks were observed in the lower angle region $\left(2 \theta<10^{\circ}\right)$, indicated the hexagonal arrays of planes (18). Although both FSM-16 and Fe-FSM-16 have almost the same XRD pattern, the intensity of the observed peaks decreased in the case of Fe-FSM-16. This showed that the ordered structure was partially lost after metal impregnation.

\section{Nitrogen adsorption-desorption isotherms}

Physical adsorption is one of the methods for the porous materials characterization and provides information about surface area, pore size, and pore size distribution. Specific surface area, pore diameter and pore volume data of the FSM-16 and Fe-FSM-16 are presented in Table 1. Specific surface area of the FSM-16 and Fe-FSM-16 were $755.1 \mathrm{~m}^{2} / \mathrm{g}$ and $581.5 \mathrm{~m}^{2} / \mathrm{g}$, respectively. It seemed that the impregnation of $\mathrm{Fe}\left(\mathrm{NO}_{3}\right)_{3} \cdot 9 \mathrm{H}_{2} \mathrm{O}$ on the FSM-16 decreased the surface area due to intrapore formation of ferric oxide. This reduction in the surface area in the case of Fe-FSM-16, were also supported by the lower values of pore diameters (from $3.6 \mathrm{~nm}$ to $2.5 \mathrm{~nm}$ ) and pore volumes (from $1.43 \mathrm{cc} / \mathrm{g}$ to $0.55 \mathrm{cc} / \mathrm{g}$ ). In combination with the XRD data, surface area measurements offered detailed information about pore architecture of the catalytic 
material. This is important for the accessibility of active sites and thus is related to the catalytic activity of the Fe-FSM-16.

The $\mathrm{N}_{2}$ adsorption-desorption isotherms of FSM-16 and Fe-FSM-16 samples are shown in Figure 2. Samples showed a well defined step at $\mathrm{P} / \mathrm{P}_{0} \approx 0.3-0.5$, which represented capillary condensation of $\mathrm{N}_{2}$ gas and uniformity of the pores (19).

\section{Effect of temperature on CNTs growth}

Temperature is an important parameter for the growth process, since the ability of a catalyst to dissociate hydrocarbon depends on the reaction temperature. Indeed, raising the reaction temperature increased the carbon formation over the catalysts (12). In order to investigate the temperature effect, experiments were performed between $500^{\circ} \mathrm{C}$ and $800^{\circ} \mathrm{C}$. Figure 3 represents the carbon deposition and the carbon yield with respect to the reaction temperature for all type of catalyst. While carbon yield was $2.88 \%$ at $600^{\circ} \mathrm{C}$, it increased to $8 \%$ at $800^{\circ} \mathrm{C}$. It was clear that, carbon yield increased with increasing temperature.

Under pyrolytic thermal conditions hydrocarbon molecules broke forming radicallic fragments; these attach to the catalyst particles and diffuse through the catalyst particles, and then led saturation level. During this process, rate determining step is diffusion of carbon from gas/metal interface to metal/carbon interface. As a result, mass flux originated from the solubility difference of carbon at gas/metal interface and metal/carbon interface. At low temperatures carbon solubility in solid solutions was very low (20). Therefore, CNTs structure was not observed at $500^{\circ} \mathrm{C}$. Beyond this temperature it seemed that higher amounts of carbon material started to deposit on the catalyst.

Figure 4 illustrates the SEM micrographs of CNTs growth over Fe- FSM-16 at $600^{\circ} \mathrm{C}$, $700^{\circ} \mathrm{C}$ and $800^{\circ} \mathrm{C}$. From SEM images, it was clear that the growth mechanism of the carbon nanotubes was tip growth. It was obviously observed from the results, that the metal particles were present at the top of the nanotube. Due to weak interaction between the metal particles and the support material, diffused carbon lifted metal particles to top of the nanotube.

Temperature had predominant effect on CNTs growth. Raising the temperature in addition to the increase of the deposited amount of CNTs also affected the morphology of the carbon nanotubes. The effect of increasing the temperature of CVD was observed as an te increase in the diameter of CNTs. Diameters of the CNTs produced at $800^{\circ} \mathrm{C}$ was bigger larger relative to those produced at lower temperatures. Probably, at higher temperatures, catalytic iron 
species merged on the FSM-16 surface, forming larger catalyst particles that caused to form wider diameter CNTs formation by tip growth (21). Moreover, Zhao et al (4) suggested possibility of acetylene pyrolysis on CNTs sidewalls, leading to tube diameter thickening.

Raising the temperature increased the carbon solubility due to enhanced diffusion and this caused the formation of iron carbide at temperatures around $500^{\circ} \mathrm{C}$. For the CNTs growth it is essential that iron carbide should decompose and form $\alpha$-Fe phase. This phase starts to form between $500^{\circ} \mathrm{C}$ and $725^{\circ} \mathrm{C}$ and stabilizes at temperatures above $725^{\circ} \mathrm{C}$ (12). After the formation of $\alpha$-Fe phase which is the active form for graphite precipitation, the rate of CNTs production increases rapidly. This explained why CNTs did not form at temperatures around $500^{\circ} \mathrm{C}$.

Although temperature increment led to high CNTs yield, enhanced diffusion of carbon and carbon solubility contributed to increase of average diameter of CNTs. For appropriate yield, the reaction temperature was chosen to be $700{ }^{\circ} \mathrm{C}$.

The sample in powder form was investigated at high magnifications using Transmission Electron Microscopy (TEM) in order to analyze the microstructure of CNTs in detail. Brightfield (BF) TEM image in Figure 5 shows the general geometry of nanotubes grown over 4 wt \% Fe-FSM-16 particles. High-resolution transmission electron (HRTEM) micrograph in Figure 6 reveals the multilayer sidewalls of an individual MWCNT with a diameter of $40 \mathrm{~nm}$, in which hollow and tubal structures were observed.

\section{Effect of Acetylene Flow Rate}

In order to investigate effect of the flow rate of acetylene on the amount of carbon nanotube formed, the experiments were carried out at flow rates of acetylene in the range of 40 $120 \mathrm{~mL} / \mathrm{min}$ at $700^{\circ} \mathrm{C}$ with for $30 \mathrm{~min}$ reaction time.

The carbon deposition and the carbon conversion percentages as a function of acetylene flow rate are given in Figure 7. According to above this analysis (Figure 5), carbon amount deposited on the catalyst increased with increasing flow rate of acetylene up to $80 \mathrm{~mL} / \mathrm{min}$. Beyond the flow rate of $80 \mathrm{~mL} / \mathrm{min}$ the amount of carbon deposition reached to constant values. It seemed that the acetylene flow rate of $80 \mathrm{~mL} / \mathrm{min}$ was a limiting value for the formation of carbon nanotubes, higher values of acetylene flow did not increase the amount of carbon nanotubes formed. Probably for flow rates greater than $80 \mathrm{~mL} / \mathrm{min}$ there was no mass flux between acetylene/metal interface since they reached equilibrium. Due to carbon transfer 
limitations between the hydrocarbon source and the metal interface, carbon conversion might have decreased with increased flow rate of acetylene.

Acetylene flow rate did not have any significant effect on the morphology of the resulting CNTs. The resulting CNTs are shown in Figure 8. It was observed that the diameters of the CNTs diameter was were almost same and it changed in the range of 20-35 nm.

\section{Raman Spectroscopy}

Raman spectroscopy is a powerful tool for the characterization of the synthesized CNTs with respect to their diameter and quality of nanotubes (22). It is possible to distinguish SWCNTs and MWCNTs from each other with the aid of the Raman spectroscopical data. Radial breathing mode (RBM) features appear over lower wavenumber region. RBM modes corresponds coherent vibration of $\mathrm{C}$ atoms in radial direction. Raman bands appearing between $120-350 \mathrm{~cm}^{-1}$ are related to the SWCNTs for diameters in the range of $0.7-2 \mathrm{~nm}(22,23)$. The Raman bands at higher wavenumber region are both characteristic for SWCNTs and MWCNTs. The band in the range of 1500-1605 $\mathrm{cm}^{-1}$ is referred $\mathrm{G}$ band (Graphite Band). G band correspond to vibration of $\mathrm{C}-\mathrm{C}$ bond of graphene sheet. D band (Disorder Band) is usually observed at in the range $1250-1450 \mathrm{~cm}^{-1}$. D band is the result of disordered-induced vibration of $\mathrm{C}-\mathrm{C}$ bond. $D / G$ peak intensity ratio is an index for determining the CNTs structure (22).

The effect of CVD temperature on the structure of CNTs over 4 wt \% Fe-FSM-16 were demonstrated in the Raman spectrum demonstrated in Figure 9. Presence of D and G bands indicated the formation of the that graphitic carbon was formed. Since there was not any peak observed in the RBM region, probably the CNTs produced were MWCNTs. While the G band was seen at $1589 \mathrm{~cm}^{-1}$ of the carbon nanotubes produced at $600^{\circ} \mathrm{C}$, this band appeared at 1592 $\mathrm{cm}^{-1}$ in the spectra of the products obtained at $700^{\circ} \mathrm{C}$ and $800^{\circ} \mathrm{C}$. The $\mathrm{D}$ band position changed from $1341 \mathrm{~cm}^{-1}\left(600^{\circ} \mathrm{C}\right.$ and $\left.700^{\circ} \mathrm{C}\right)$ to $1350 \mathrm{~cm}^{-1}\left(800^{\circ} \mathrm{C}\right)$. Moreover, as the CVD temperature increased, intensities of both D and G band decreased.

The comparison of the intensity ratios of these two peaks were given in Table 2. It was observed that increasing temperature resulted decrease in the intensity of D and G bands. In the temperature range of $600-800^{\circ} \mathrm{C}, D / G$ peak intensity ratios were $0.81,084$, and 0.87 . These indicated that the structure of the MWNTs changed with CVD temperature. At higher growth temperatures $\left(700^{\circ} \mathrm{C}\right.$ and $\left.800^{\circ} \mathrm{C}\right), \mathrm{D}$ band became stronger and the degree of crystalline perfection of the CNTs decreased. Decomposition of acetylene was very rapid at higher 
temperatures and this rapid decomposition resulted in excess amorphous carbon formation on the catalyst surface. As a result, excess carbon deactivated the Fe particles and this prevented the growth of perfect CNTs on the catalyst particles.

Effect of the acetylene flow rate on the structure of CNTs was also investigated by Raman spectroscopy. Raman spectra of the CNTs formed over 4 wt \% Fe-FSM-16 at 40 $\mathrm{mL} / \mathrm{min}, 80 \mathrm{~mL} / \mathrm{min}, 100 \mathrm{~mL} / \mathrm{min}$, and $120 \mathrm{~mL} / \mathrm{min}$ acetylene flow rates were shown in Figure 9. There was not any peak in the RBM region in the Raman spectrum, this indicated that SWCNTs were not produced but MWCNTs were formed.

The ratio of the intensities of $D / G$ ratios were shown in Table 3 . Intensities of $G$ and $D$ bands increased with increasing acetylene flow rate, however, the ratio of these two band stayed constant indicating that flow rate of acetylene did not have any significant effect on the quality of CNTs.

TGA

TGA measurements were performed in order to investigate the quality of CNTs. Measurements were performed under an air atmosphere with a flow rate $50 \mathrm{ml} / \mathrm{min}$, at a linear heating rate of $5^{\circ} \mathrm{C} / \mathrm{min}$. TG and DTA curves of samples are shown in Figure 10. It was noted that increasing temperature resulted in weight loss due to burning out of carbon. TG curve exhibited one sequential zone of $375-817^{\circ} \mathrm{C}$. Approximately, $60 \mathrm{wt} \%$ of the total mass burned out at temperatures below $817^{\circ} \mathrm{C}$. According to literature $(24,25)$, mass loss over the range of $300-400^{\circ} \mathrm{C}$ corresponds to combustion of amorphous carbon and burning of CNTs takes places at $400-650^{\circ} \mathrm{C}$. Residual mass after the TG experiments obtained in the present work corresponded to $40 \mathrm{wt} \%$ of the total mass of the products and this probably contained oxides of the catalytic iron that was together with the carbonaceous products.

The onset, inflection and end temperatures were listed in Table $4 . \mathrm{CNTs}$ grown at $600^{\circ} \mathrm{C}$, $700^{\circ} \mathrm{C}$, and $800^{\circ} \mathrm{C}$ started to burn at $375^{\circ} \mathrm{C}, 436^{\circ} \mathrm{C}$, and $518^{\circ} \mathrm{C}$, respectively. Weight losses below $400^{\circ} \mathrm{C}$ indicated that burning of amorphous carbon. Graphite particles are more stable compared to amorphous carbon and burned at higher temperatures. With increasing temperature, inflection temperature shifted to higher temperatures. TG-DTA data proved that CNTs grown at higher temperature had better crystalline structure compared to low temperature grown (22).

Effect of acetylene flow rate on graphitization of CNTs grown at $700^{\circ} \mathrm{C}$ was investigated. TG and DTA curves of samples are illustrated in Figure 11. When the flow rate increased from 
$40 \mathrm{~mL} / \mathrm{min}$ to $120 \mathrm{~mL} / \mathrm{min}$, TG curves exhibited one sequential zone. Furthermore, residual mass was $50 \mathrm{wt} \%$ of the total mass. Table 4 revealed the decomposition temperature of formed CNTs. It was noted that, the peak of maximum weight loss and inflection temperature shifted toward to higher temperatures with increasing acetylene flow rate. With increasing the flow rate of acetylene above $60 \mathrm{~mL} / \mathrm{min}$, inflection temperature did not change. It was found that, for flow rates higher than $60 \mathrm{~mL} / \mathrm{min}, \mathrm{CNTs}$ had better crystalline structure.

\section{Conclusion}

In this study, the effect of CVD temperatures and acetylene flow rates were investigated in the production of CNTs over $4 \mathrm{wt} \%$ Fe-FSM-16 catalysts. Catalysts were prepared by wet impregnation method.

- Experiments were conducted at $500^{\circ} \mathrm{C}, 600^{\circ} \mathrm{C}, 700^{\circ} \mathrm{C}$, and $800^{\circ} \mathrm{C}$ and the effect of the reaction temperatures was examined for $\mathrm{CNT}$ growth. At $500^{\circ} \mathrm{C}$, no CNTs grown were observed because of low carbon solubility in metal particles. Higher reaction temperatures contributed to significant amount of carbon deposited on the catalyst and carbon conversion due to enhance diffusion of carbon through the metal particles. It was known that, at higher temperatures, large Fe particles formed and diameter of the CNTs was increase.

- The effect of acetylene flow rate on CNTs production of $4 \mathrm{wt} \% \mathrm{Fe}-\mathrm{FSM}-16$ at $700^{\circ} \mathrm{C}$ using $40 \mathrm{~mL} / \mathrm{min}-120 \mathrm{~mL} / \mathrm{min}$ acetylene flow rate was studied. The carbon amount deposited on the Fe catalyst increased until the acetylene flow rate reached $80 \mathrm{ml} / \mathrm{min}$ and it was constant with increasing flow rate. This behavior was the result of equilibrium of carbon concentrations between acetylene/metal interfaces. Moreover, SEM images demonstrated that CNTs diameter was almost same with increasing acetylene flow rate.

- High-resolution transmission electron micrographs of samples reveal the multilayer sidewalls of individual MWCNTs with diameter of $40 \mathrm{~nm}$, in which hollow and tubal structures were observed.

- Raman spectroscopical results clearly indicated that the CNTs produced were MWCNTs. Some of the formed CNTs were also examined by TGA for having an idea about quality of CNTs. Thermal decomposition differences were observed during the burning of CNTs. 
At low temperatures, CNTs started decomposition below $400^{\circ} \mathrm{C}$ due to burning of amorphous carbon. As the CVD, temperature increased, samples contained less amorphous carbon and more CNTs thus burning temperatures shifted toward to higher temperatures. On the other hand, TGA results supported the Raman results for CNT production under different acetylene flow rate. It was found that, inflection temperature was almost same.

\section{Acknowledgements}

This work was supported by the Scientific and Technological Research Council of Turkey (TUBITAK) with the Project No. 109M214.

High-resolution transmission electron micrographs of samples were kindly recorded by Prof. Dr. Christian Gspan of Institute for Electron Microscopy and Fine Structure Research, Graz University of Technology, Steyrergasse, Graz, Austria.

\section{References}

1. Popov V.N. (2004) Carbon nanotubes: properties and application. Materials Science \& Engineering R-Reports, 43: 61.

2. Somanathan T., Pandurangan, A. and Sathiyamoorthy D. (2006) Catalytic influence of mesoporous Co-MCM-41 molecular sieves for the synthesis of SWNTs via CVD method. Journal of Molecular Catalysis A-Chemical, 256: 193.

3. Paradise M. and Goswami T. (2007) Carbon nanotubes - Production and industrial applications. Materials \& Design, 28: 1477.

4. Zhao, Q., LiY.H., Zhou X.P., Jiang T.S., Li C.S., and Yin H.B. (2010) Synthesis of multi-wall carbon nanotubes by the pyrolysis of ethanol on Fe/MCM-41 mesoporous molecular sieves. Superlattices and Microstructures, 47: 432.

5. Oncel Ç. and Yürüm Y. (2006) Carbon nanotube synthesis via the catalytic CVD method: A Review on the Effect of Reaction. Parameters, Fullerenes, Nanotubes and Carbon Nanostructures, 14: 17-37.

6. Shanov V., Yun Y., Shulz M.J. (2006) Synthesis and characterization of carbon nanotube materials. Journal of University of Chemical Technology and Metallurgy, 41: 377. 
7. Dumanli A. and Yürüm Y. (2011) Carbon nanotube and nanofiber growth on Zn-based catalysts. Fullerenes, Nanotubes, and Carbon Nanostructures, 19: 155.

8. Kukovecz A., Konya Z., Nagaraju N., Willems I., Tamasi A., Fonseca A., Nagy J. B., Kiricsi I. (2000) Catalytic synthesis of carbon nanotubes over Co, Fe and $\mathrm{Ni}$ containing conventional and sol-gel silica-aluminas. Physical Chemistry Chemical Physics, 2: 3071.

9. Hernadi K., Fonseca A., Nagy J.B., Siska A., Kiricsi I. (2000) Production of nanotubes by the catalytic decomposition of different carbon-containing compounds. Applied Catalysis A: General, 199: 245.

10. Duesberg G.S., Graham A.P., Liebau M., Seidel R., Unger E., Kreupl F., Hoenlein W. (2003) Growth of isolated carbon nanotubes with lithographically defined diameter and location. Nano Letters, 3: 257.

11. Klinke C., Bonard J.M., Kern K. (2001) Comparative study of the catalytic growth of patterned carbon nanotube films. Surface Science, 492: 195.

12. Ermakova M.A., Ermakov D.Y., Chuvilin A.L., Kuvshinov G. (2001) Decomposition of methane over iron catalysts at the range of moderate temperatures: The influence of structure of the catalytic systems and the reaction conditions on the yield of carbon and morphology of carbon filaments. Journal of Catalysis, 201: 183.

13. Venegoni D., Serp P., Feurer R., Kihn Y., Vahlas C., Kalck P. (2002) Parametric study for the growth of carbon nanotubes by catalytic chemical vapor deposition in a fluidized bed reactor. Carbon, 40: 1799.

14. Cho Y.S., Choi G.S., S. Hong Y., Kim D. (2002) Carbon nanotube synthesis using a magnetic fluid via thermal chemical vapor deposition. Journal of Crystal Growth, 243: 224.

15. Atchudan R., Pandurangan A., Somanathan T. (2009) Bimetallic mesoporous materials for high yield synthesis of carbon nanotubes by chemical vapor deposition techniques. Journal of Molecular Catalysis A-Chemical, 309: 146.

16. Kobayashi K., KitauraR., Kumai Y., Goto Y., Inagaki S., Shinohara H. (2009) Fabrication of single-wall carbon nanotubes within the channels of a mesoporous material by catalyst-supported chemical vapor deposition. Carbon, 47: 722.

17. Inagaki S., Sakamoto Y., Fukushima Y., Terasaki O. (1996) Pore wall of a mesoporous molecular sieve derived from kanemite. Chem. Mater, 8: 2089. 
18. Inagaki S., Koiwai A., Suzuki N., Fukushima Y., and Kuroda K. (1996) Syntheses of highly ordered mesoporous materials, FSM-16, derived from kanemite. Bulletin of the Chemical Society of Japan, 69: 1449.

19. Ghattas M. S. (2006) Cobalt modified mesoporous FSM-16 silica: Characterization and catalytic study. Microporous and Mesoporous Materials, 97: 107.

20. Pollack H. W. (1988) Materials Science and Metallurgy, Prentice Hall.

21. Kukovitsky E.F., L'vov S.G., Sainov N.A., Shustov V.A., Chernozatonskii L.A. (2002) Correlation between metal catalyst particle size and carbon nanotube growth. Chemical Physics Letters, 355: 497.

22. Chen C.M., Dai Y.M., Huang J.G., Jehng J.M. (2006) Intermetallic catalyst for carbon nanotubes (CNTs) growth by thermal chemical vapor deposition method. Carbon, 44: 1808.

23. Dresselhaus M.S., Dresselhaus G., Saito R., Jorio A. (2005) Raman spectroscopy of carbon nanotubes. Physics Reports-Review Section of Physics Letters, 409: 47.

24. Scaccia S., Carewska M., Prosini P.P. (2005) Study of purification process of singlewalled carbon nanotubes by thermoanalytical techniques. Thermochimica Acta, 435: 209.

25. Lee C.J., Park J., Huh Y., Lee J.Y. (2001) Temperature effect on the growth of carbon nanotubes using thermal chemical vapor deposition. Chemical Physics Letters, 343:33. 


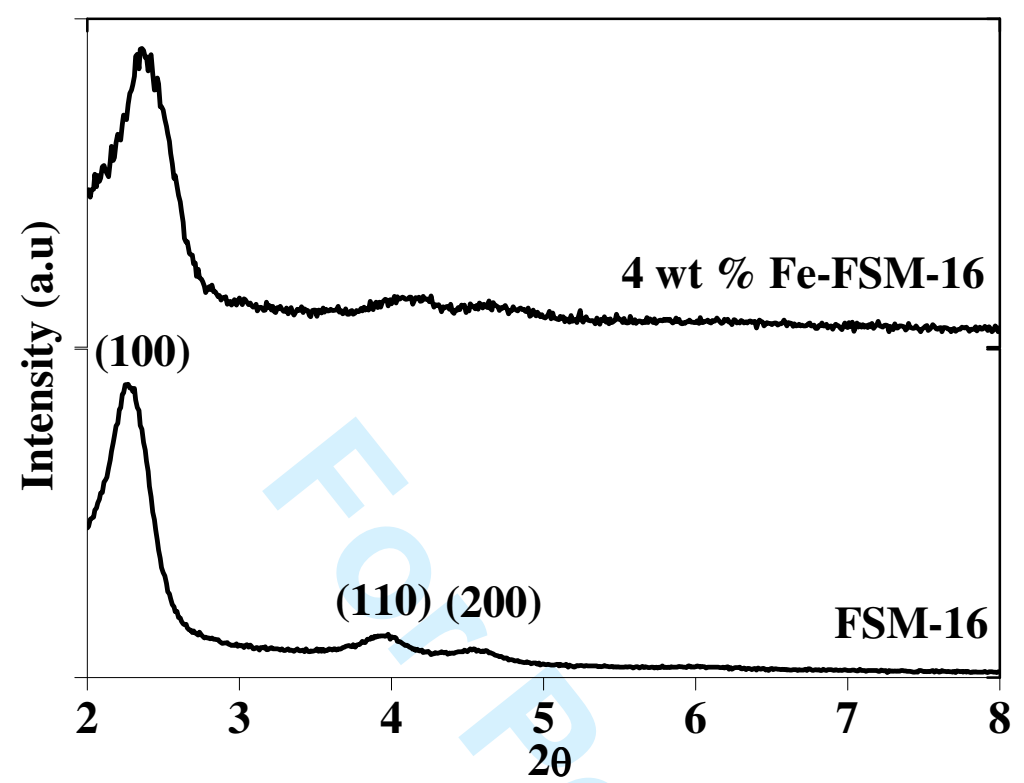

Figure 1. XRD pattern of FSM-16 and Fe impregnated FSM-16. 


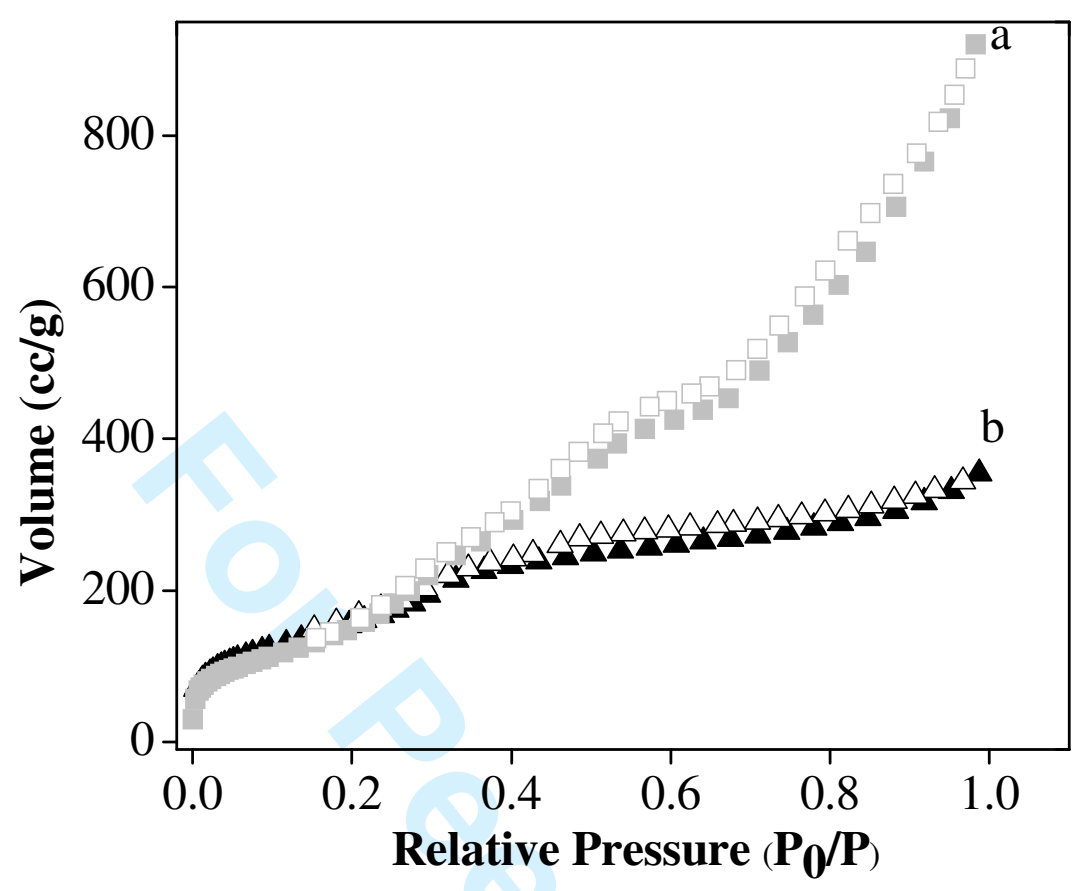

Figure 2. Adsorption-desorption isotherms for (a) FSM-16 and (b) 4 wt \% Fe-FSM-16 

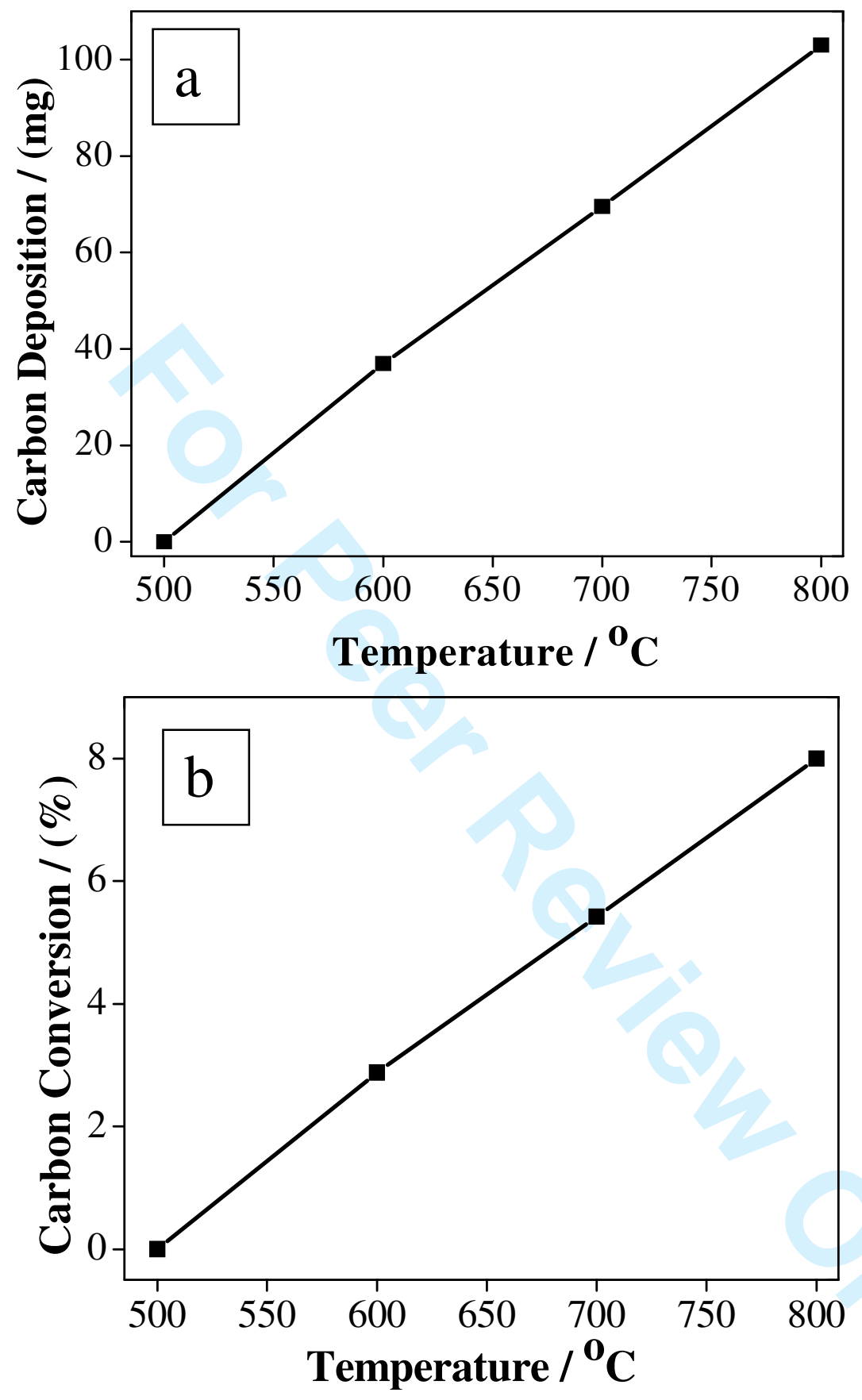

Figure 3. a) Carbon deposition and b) Carbon conversion change as a function of reaction temperature. 


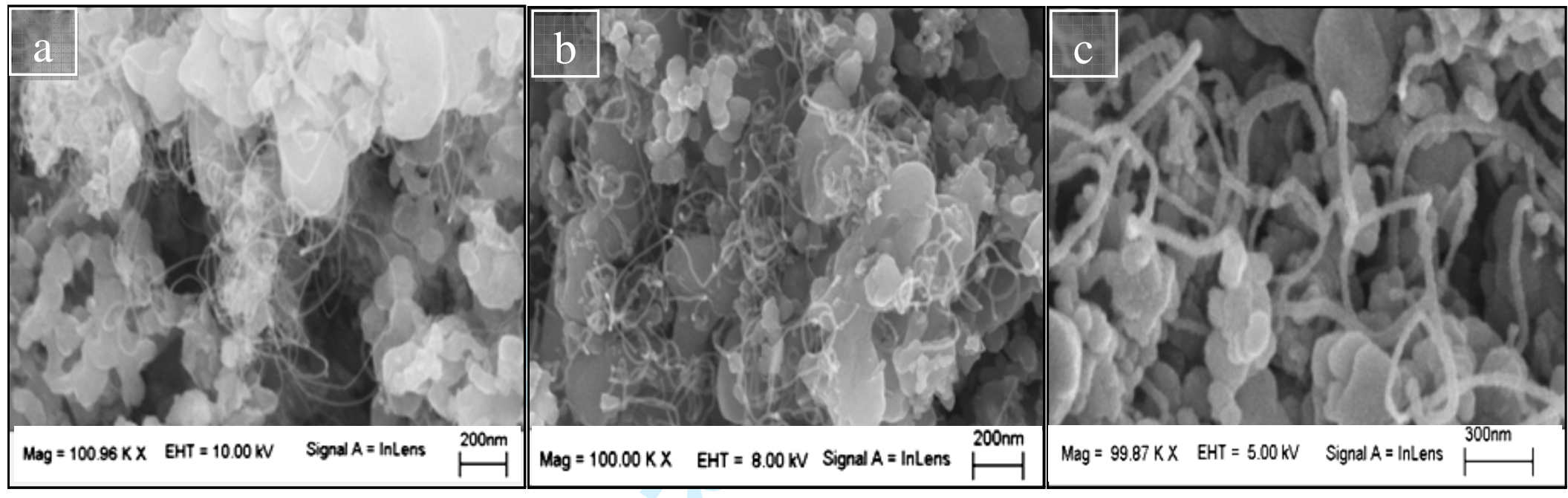

Figure 4. CNTs growth over 4 wt $\%$ FSM-16 at (a) $600^{\circ} \mathrm{C}$, (b) $700^{\circ} \mathrm{C}$, (c) $800^{\circ} \mathrm{C}$. 


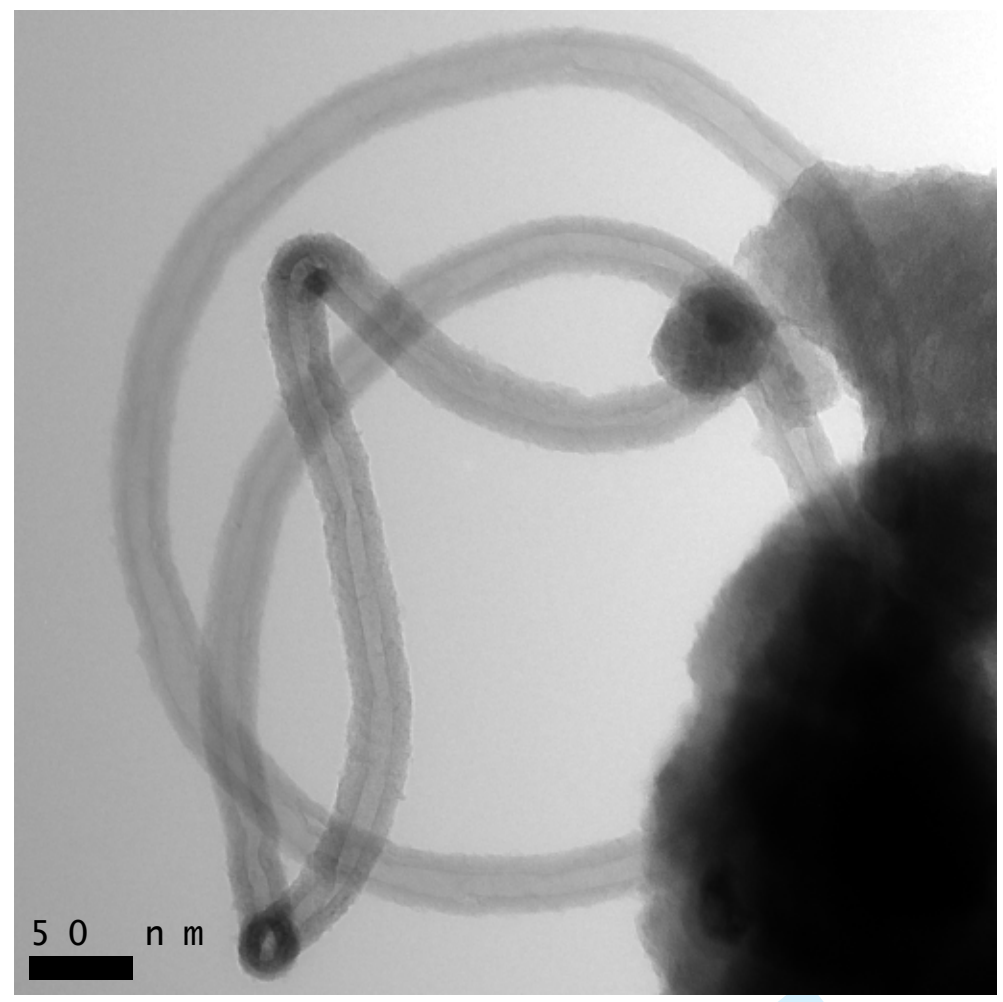

Figure 5. Multi-walled carbon nanotubes grown over 4 wt \% Fe-FSM-16 particles. 


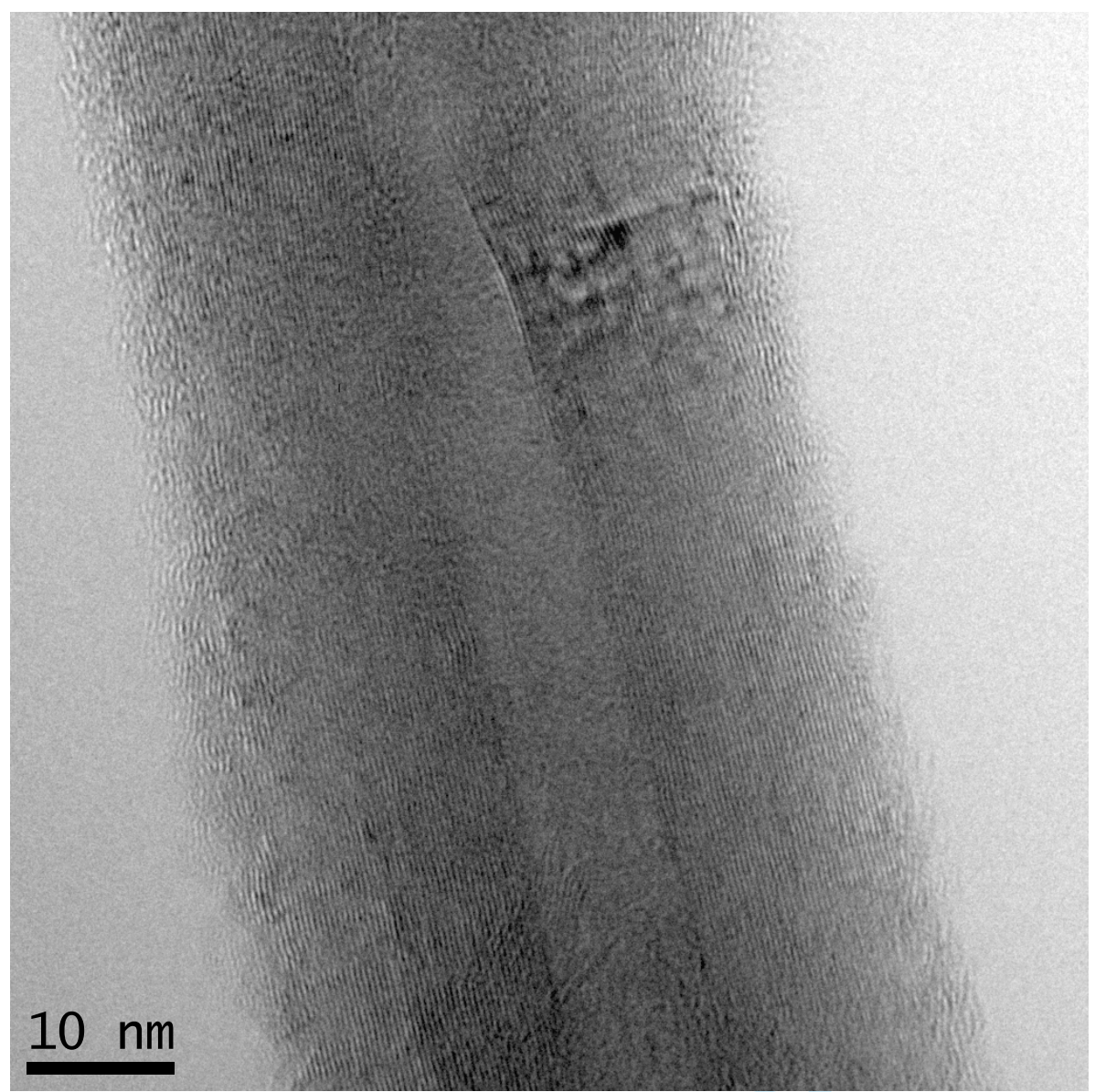

Figure 6. HRTEM micrograph of an individual multi-walled carbon nanotubes. 


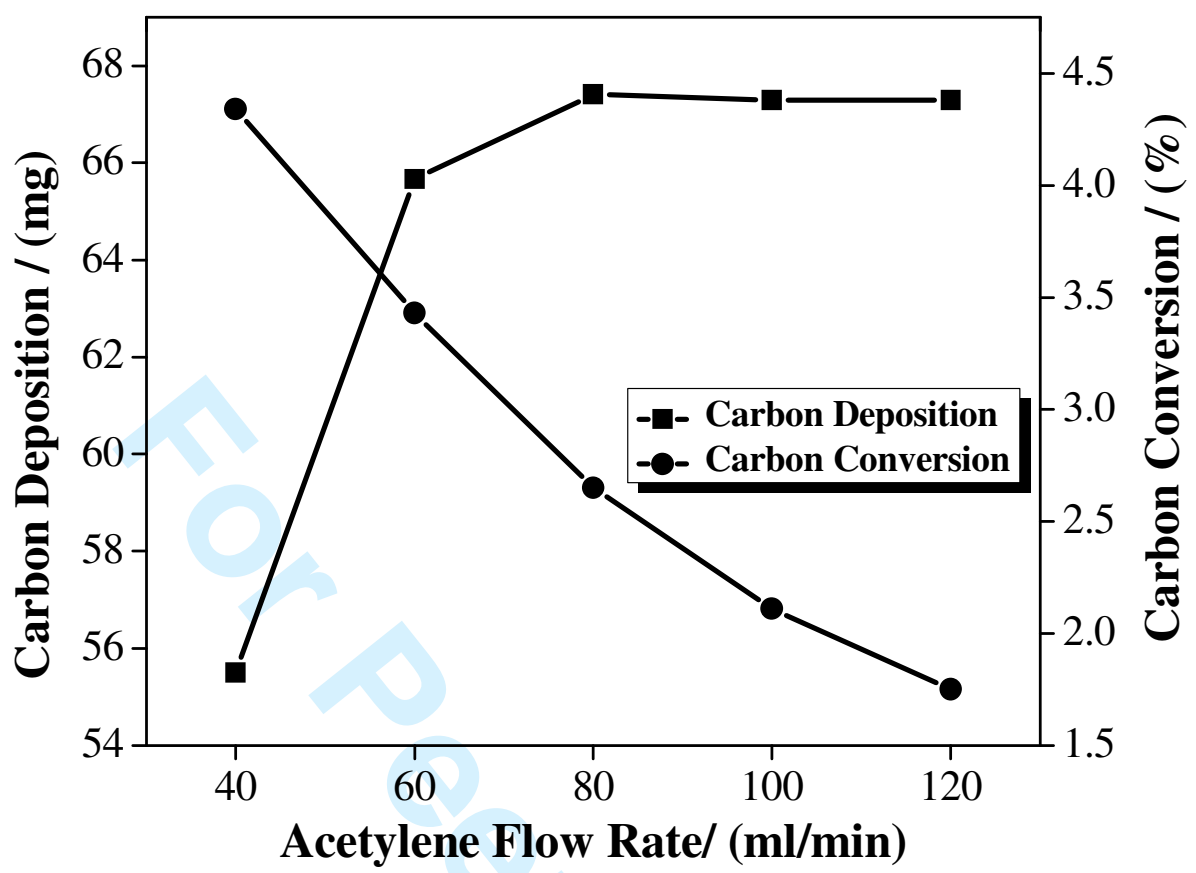

Figure 7. Carbon deposition and conversion change as a function of acetylene flow rate. 

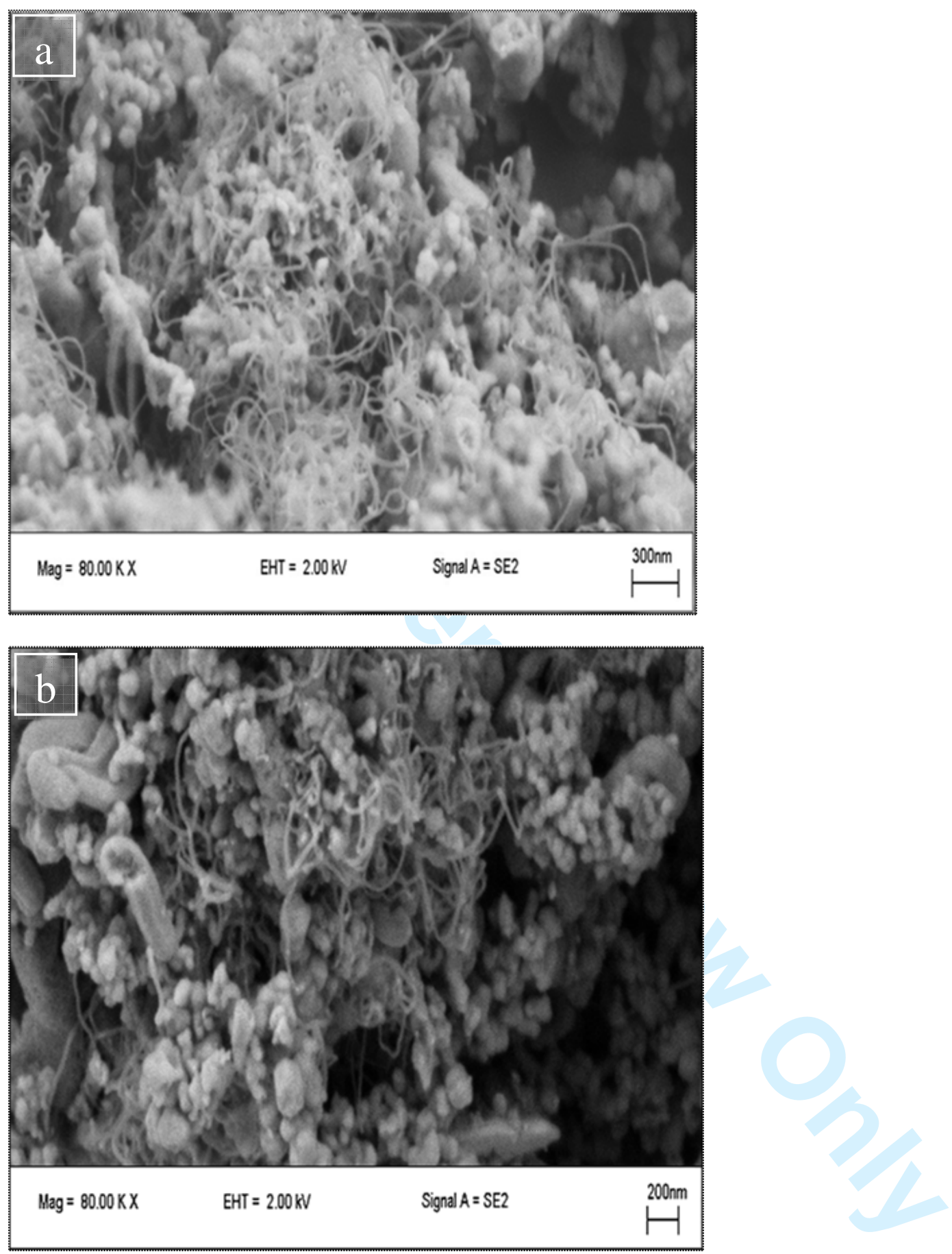

Figure 8. CNTs growth over 4 wt \% Fe- FSM-16 with a) $80 \mathrm{ml} / \mathrm{min}$ acetylene flow rate, b) 120 $\mathrm{ml} / \mathrm{min}$ acetylene flow rate. 

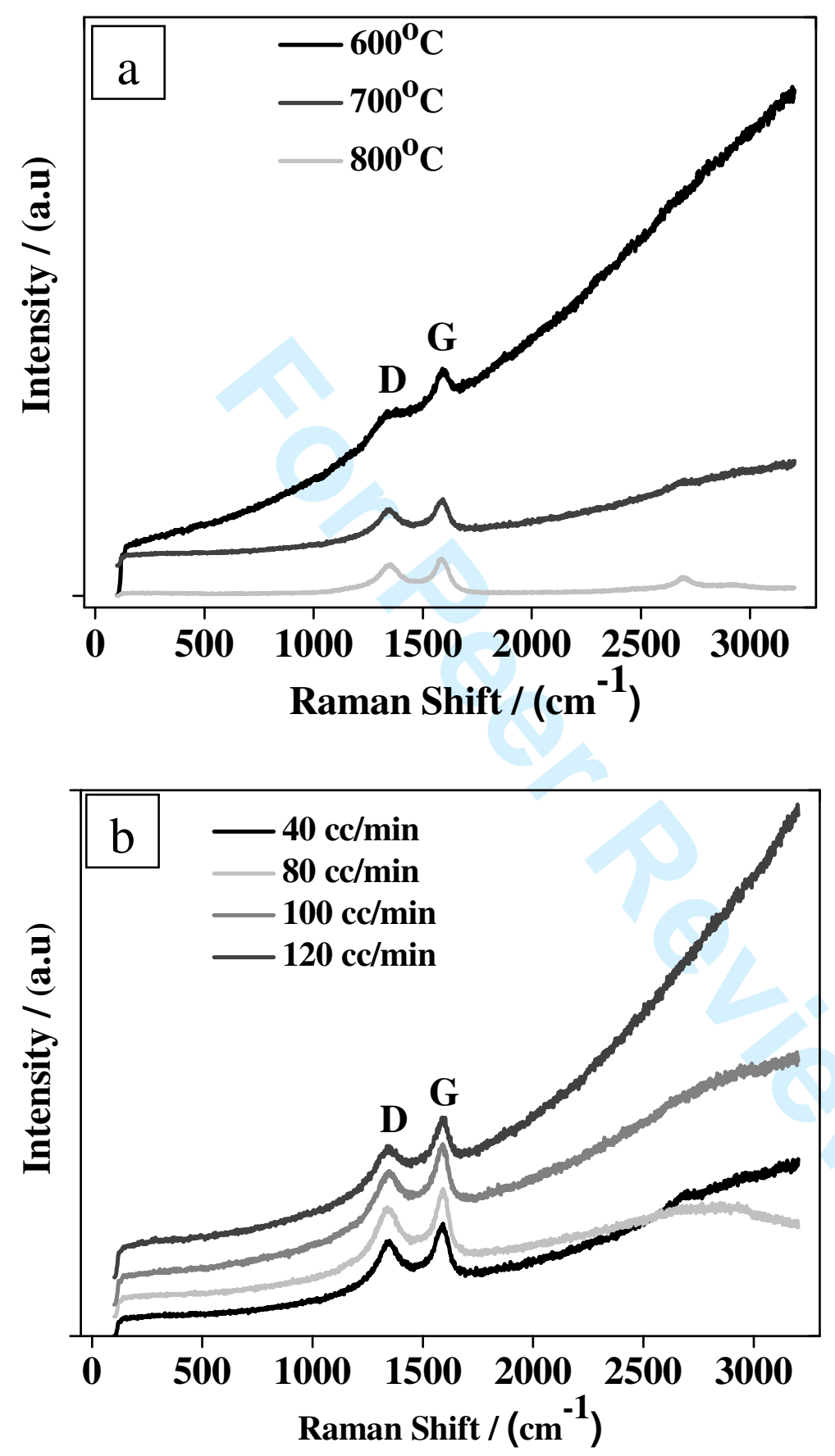

Figure 9. Raman spectra of carbon deposits on 4 wt \% Fe-FSM-16, a) Effect of reaction temperature, b) Effect of acetylene flow rate. 

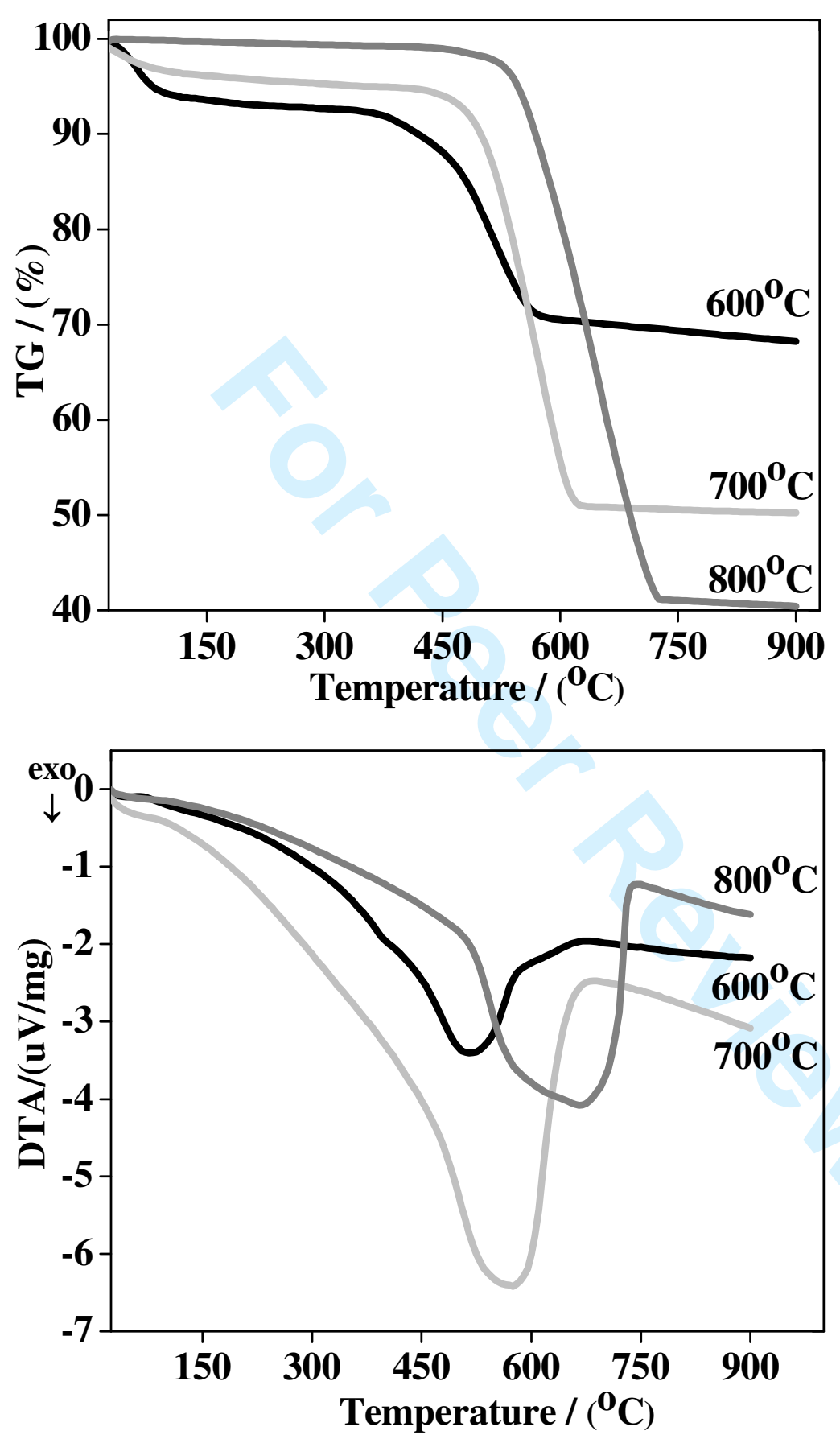

Figure 10. TGA thermograms and DTA curves of CNTs. 

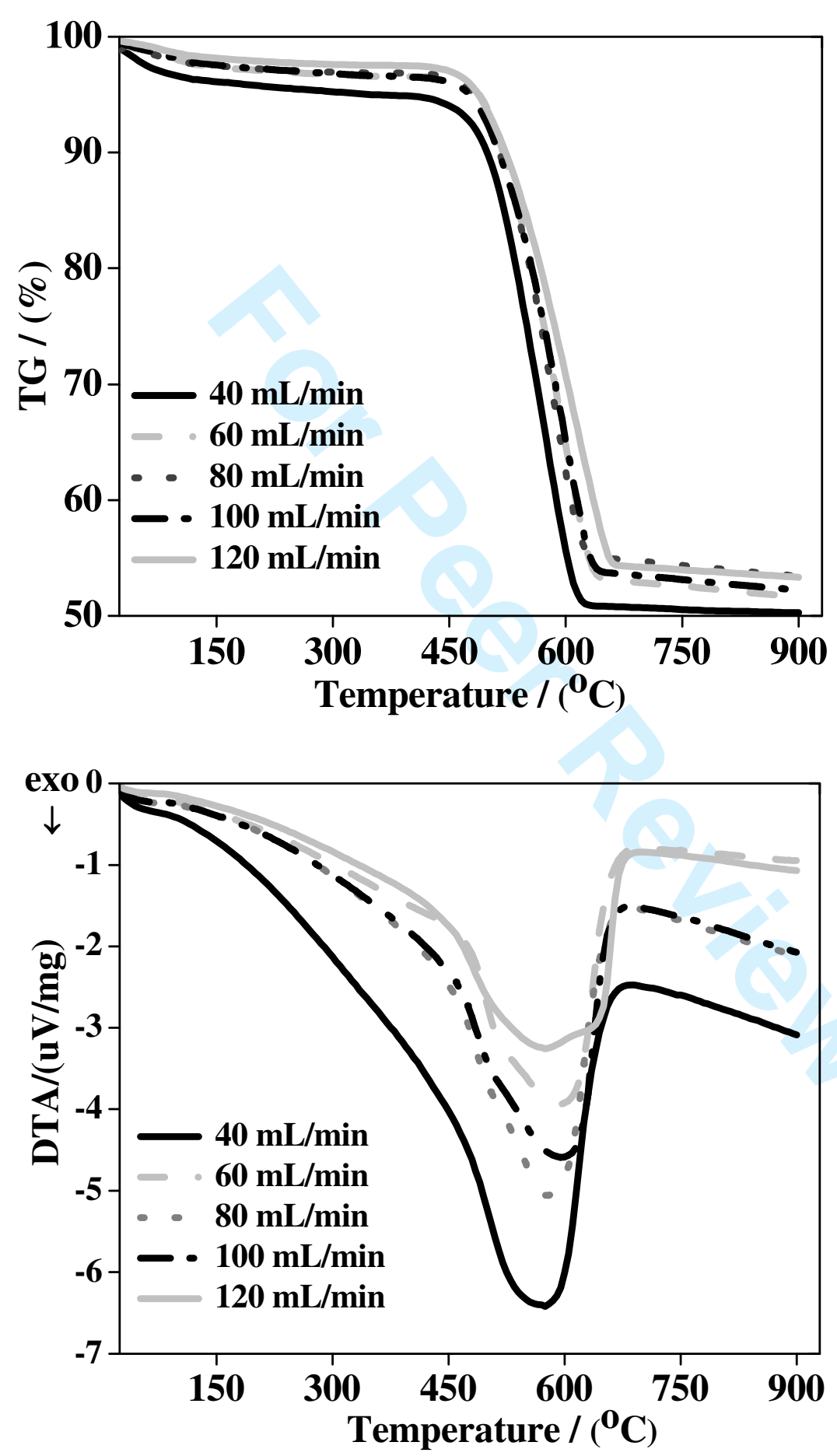

Figure 11. TGA thermograms and DTA curves of growth of CNTs with various acetylene flow rate. 
Tables

Table 1. Results of specific surface area, pore size and pore volume of catalysts.

\begin{tabular}{cccc}
\hline Sample & $\begin{array}{c}\text { Specific Surface } \\
\text { Area }\left(\mathrm{m}^{2} / \mathrm{g}\right)\end{array}$ & $\begin{array}{c}\text { Average Pore } \\
\text { Diameter }(\mathrm{nm})\end{array}$ & $\begin{array}{c}\text { Total Pore Volume } \\
(\mathrm{cc} / \mathrm{g})\end{array}$ \\
\hline FSM-16 & 755.1 & 3.6 & 1.43 \\
$4 \mathrm{wt} \%$ Fe- FSM-16 & 581.5 & 2.5 & 0.55 \\
\hline
\end{tabular}


Table 2. Parameters of D and G band for carbon deposits on 4 wt $\%$ Fe -FSM-16 at different temperature

\begin{tabular}{llllll}
\hline & & & $\begin{array}{l}\text { Absolute } \\
\text { Intensity }\end{array}$ & $\begin{array}{l}\text { Absolute } \\
\text { Intensity }\end{array}$ & $\mathrm{I}_{\mathrm{D}} / \mathrm{I}_{\mathrm{G}}$ \\
& Remperature & & \\
& (D-Band) & Raman Shift $\left(\mathrm{cm}^{-1}\right)$ & & \\
(D-Band) & (G-Band) & \\
\hline $600^{\circ} \mathrm{C}$ & 1341 & 1589 & 7981 & 9824 & 0.81 \\
$700^{\circ} \mathrm{C}$ & 1341 & 1592 & 2426 & 2880 & 0.84 \\
$800^{\circ} \mathrm{C}$ & 1350 & 1592 & 1378 & 1589 & 0.87 \\
\hline
\end{tabular}


Table 3: Parameters of D and G band for carbon deposits on 4 wt \% Fe -FSM-16 produced with different acetylene flow rates at $700^{\circ} \mathrm{C}$

\begin{tabular}{cccccc}
\hline & & & $\begin{array}{c}\text { Absolute } \\
\text { Intensity }\end{array}$ & $\begin{array}{c}\text { Absolute } \\
\text { Intensity }\end{array}$ & $\mathrm{I}_{\mathrm{D}} / \mathrm{I}_{\mathrm{G}}$ \\
& Raman Shift $\left(\mathrm{cm}^{-1}\right)$ & Raman Shift $\left(\mathrm{cm}^{-1}\right)$ & $\begin{array}{c}\text { (D-Band) } \\
(\mathrm{G}-\text { Band })\end{array}$ & \\
\hline $40 \mathrm{~mL} / \mathrm{min}$ & 1341 & $(\mathrm{G}-$ Band $)$ & 2426 & 2880 & 0.84 \\
$80 \mathrm{~mL} / \mathrm{min}$ & 1356 & 1592 & 2550 & 3060 & 0.83 \\
$100 \mathrm{~mL} / \mathrm{min}$ & 1358 & 1579 & 3380 & 4093 & 0.83 \\
$120 \mathrm{~mL} / \mathrm{min}$ & 1356 & 1585 & 3335 & 4004 & 0.83 \\
\hline
\end{tabular}


Table 4. Onset, inflection and end temperature obtained from DTG curve

\begin{tabular}{llll}
\hline Sample & $\begin{array}{l}\text { Onset } \\
\text { Temperature }\end{array}$ & $\begin{array}{l}\text { Inflection } \\
\text { Temperature }\end{array}$ & $\begin{array}{l}\text { End } \\
\text { Temperature }\end{array}$ \\
\hline CNTs-600 $\mathrm{C}$ & 375 & 513 & 666 \\
CNTs-700 $\mathrm{C}(40 \mathrm{~mL} / \mathrm{min})$ & 436 & 573 & 686 \\
CNTs-800 $\mathrm{C}$ & 518 & 666 & 817 \\
$\mathrm{CNTs}-60 \mathrm{~mL} / \mathrm{min}$ & 449 & 591 & 700 \\
$\mathrm{CNTs}-80 \mathrm{~mL} / \mathrm{min}$ & 431 & 578 & 726 \\
CNTs- $100 \mathrm{~mL} / \mathrm{min}$ & 443 & 597 & 724 \\
$\mathrm{CNTs}-120 \mathrm{~mL} / \mathrm{min}$ & 446 & 573 & 713 \\
\hline
\end{tabular}

